\title{
Mobile phones as cultural resources for learning - an analysis of mobile expertise, structures and emerging cultural practices
}

\author{
Ben Bachmair, Norbert Pachler und John Cook
}

If it is the case that mobile devices, with their specific social and technological structures and attendant cultural practices, have become an integral part of everyday life, then the educational field has to react. But how and who? Fact is that mobile devices have reached and become fully integrated in everyday life, worldwide and across social milieus. This development is «ubiquitous» (e.g. Haythornthwaite, 2008, Beale 2007, Nyiri 2002) and is accompanied by an increase in individualisation enabled and necessitated by a variety of mobile devices characterised by media convergence. Education must ask questions about the impact of these irreversible trends on the personal development of young people and about its role in mediating them as well as about their impact on individual agency of young people in the context of emerging socio-cultural structures (see Stald 2007). It must also ask questions about mobile devices as media with application for learning. The response to the second issue, mobiles and learning, has so far been a negative one. Worldwide more schools than not prohibit mobile devices, mobile phones as well as MP3-players, small game consoles etc. Rather than embrace them as tools for learning, they address them as objects for critical media education and media literacy. It is currently in the main early adopters, be they individuals (see e.g. http://www.olliebray.typepad.com/olliebraycom/ accessed Jan. 12 ${ }^{\text {th }}$ 2009), (specialist) institutions (see e.g. the "Australian Flexible Learning Network» at http://e-standards.flexiblelearning.net.au/topics/mlearn.htm accessed Jan. $12^{\text {th }}$ 2009) or professional bodies (e.g. the International Association for Mobile Learning at http://mlearning.noe-kaleidoscope.org/projects accessed on Jan. 12 $2^{\text {th }}$ 2009) that are exploring the interrelationship of mobiles and formal learning but not the mainstream of educational institutions. The Becta research report «Emerging technologies for learning» (Volume 3, 2008) shows one way of conceptualising mobile media, namely as curricular resources within network systems. In it Mark van't Hooft (2008) relates «mobile, wireless, connected information clouds» with learning, with mobile phones acting as learning resources. The emphasis on connectivity in this example suggests that technology and its functionalities are defining the mobile phone's application for learning. But not only is the idea of media as resources for learning an old one (it derives from the transfer of film into the school in the 1940s to the 1960s), but mobile phones are also not necessarily 
restricted to application within a positivist pedagogic frame, i.e. the matching of mobile applications to learning requirements for the purposes of innovating approaches to teaching an learning without engaging in questions around the value added. Mike Sharples et al. (2007) depict educational use of mobile media as resources of the «mobile age». Avoiding for the moment the term 〈resource〉, these new versions of highly individualized media or technologies are understood as part of communication, which is also an integral activity of the school. Of course, school communication concentrates on learning and knowledge as part of conversations, reflection, interaction, commentaries etc., but are these media not similarly part of conversation, reflection, interaction, commentaries etc. in the everyday lives of young people and even of children? Sharples et al. $(2007$, p. 227) refer explicitly to Laurillard's Conversational Framework (2002) as a didactic concept for learning: «Learning is a continual conversation with the external world and its artefacts, with oneself, and also with other learners and teachers.»

Using mobile media as learning resources is a legitimate education rationale, but it needs to be embedded in a wider frame than «conversation». Beyond conversation, of course, lie cultural practices which are integrated in, and determined by the school's cultural «scripts) around the «business) of learning, but at the same time emerge from specific socio-cultural structures like the individualised, mobilised mass communication. Therefore, this paper tries to describe and analyse mobile media within the context of media convergence in everyday life by way of a case study of a boy who is using his mobile for treading a tightrope between his everyday life culture and that dominant in society, to which the school and its learning practices belong. This attendant conflict opens the possibility of identifying mobile media within the context of media convergence as cultural resources for participation, although the participation is not visible at face value. Functionally, knowledge, which is a main pursuit of school, is also a cultural resource. Knowledge, like media, is a cultural resource, which opens up, or obstructs participation in society. Educationally, knowledge and media are cultural resources, which are no longer controlled and governed by the school.

For us the question arises how to frame, culturally, such case studies about the use of mobile media beyond a concept of media as cultural resources. Everyday life, media use, learning and personal development, we argue, has to be approached holistically. In the perspective of such a holistic rationale, everyday life, media use, learning and personal development appear within, or result from specific socio-cultural structures. These structures lead to mobile media as well as to a social disintegration, which becomes visible by the first case study presented in this paper. Following Giddens' proposal (1984) to see structures and agency interrelated, a boy like Cyrill, the subject of our fist case, developed a specific agency, which is disconnected from school and its expectations. Additionally to Giddens' structuration model of social development, cultural practices such as 
pedagogical scripts of schools or media use in everyday life are seen as important for the ongoing transformation of culture. Considering the organisation of teaching and learning in schools as a cultural practice, which tends to be sceptical towards everyday life's predominant media, our second case depicts an Indian school's relatively innovative way to use mobile phones for learning.

Another question that arises is what the specific educational rationale of such a cultural approach to mobile learning is, with mobile learning understood as an assimilation and accommodation of the relevant mass communicative structures, agency and practices. In this context, we espouse an integrative view on cultural transformation as a result of socio-cultural structures, agency and cultural practices. Cultural transformation seems to lead to specific, and mobile cultural features such as those formulated here as hypotheses:

- mobility in multimedia and multimodal spaces of activity and meaning, which are integrated also in regional cultural traditions and global entertainment systems;

- mass communication as compressed and accelerated cultural system of individualised media production und individualised cultural practices (see Eriksen 2007, pp. $33 \mathrm{ff}$ ) to which user-generated contents and contexts contribute;

- fragmented, individualised meaning-making in individualised, culturally differentiated situations, which reaches from media use to formal learning.

And a further question arises: are there specific educational, pedagogical/didactic options within this socio-cultural development? For us it is essential to understand the agency of learners within the context of cultural transformation and on that basis to develop pedagogical practices of teaching as well as attendant practices of learning with media in formal settings with reference to learning practices prevalent outside of educational institutions. We argue that the educational rationale for mobile media in the context of media convergence as a potential resource for pedagogical action in school must take heed of the emergent cultural practices of everyday life. In this view, the identification of specific agency features and their communicative adjustment within institutionalised learning practices must be high on the educational agenda. This follows the ideas of Sharples on conversation quoted above (see Laurillard 2002, 2007 and developed further below).

This brief outline of a framework of mobile media as cultural resources within emerging socio-cultural structures, agency and cultural practices attempts to reconcile nature and the industrial society in the form of a cultural ecology and deals with media as cultural resources. Not the exploitation of the mobile devices and applications for potential learning improvement is at the heart of our approach, but their communicative adaptation for learning as meaning-making and for participation in culture production and society. 
Our starting point are activities of young people and their adaptation by schools. Therefore, this paper examines two case studies in an attempt to demonstrate how to assimilate and accommodate emerging cultural practice in school-based learning. First we present a case of an excluded youth, who is at a distance to society and school, but who has developed expertise within the fast changing and converging media landscape; he uses mobile phones to capture content and can be said to be engaged in advanced media literacy activities. Our goal for providing a description and an analysis for his case is to sketch out strategies for schools on how to include students with similar characteristics, which we refer to as at-risk learners here, in meaningful educational processes. As we will show, the subject at the centre of our first case does not only act within mass communication structures, which are far removed from traditional school-based modes of communication, but also within a socio-cultural structure, which is in conflict with school and its typical discourses around learning. The society of Germany, where the case is located, like other European societies, is now segmented into various socio-cultural milieus. The second case, of a project conducted in India, is examined in order to further our understanding of how different cultural contexts may be incorporated into the structures of schools. Mobile phones, which were used in this second case together with computers, effected an opening up of the school to new approaches teaching and learning that were far removed from teacher-centred approaches and which positioned learners in cooperative, self-organised learning sets outside of school. Our analysis leads us to propose three curricular dimensions as a means of conceptualising teaching and learning practices that make use of emerging technologies. They are: media features; teacher and student discourses inside and outside school; overall educational and curricular discourse. Indeed, other authors (e.g. Haythornthwaite 2008, pp. 574) have similarly pointed to the transformative effects that new media can have on learning, arguing that they provide the underpinning for a move to ubiquitous learnings. Outside the classroom learners are building up new rich media literacies as they create their own habitus of learning in everyday life. We propose that schools should, and ultimately must, recognise and embrace this change. However, we are aware that such a perspective provides a challenge to our conceptions of where the boundaries of formal education are positioned.

\section{Mobile phones as cultural resource and their appropriation within educational structures and cultural practices}

Increasingly electronic mobile devices, especially mobile phones with a wide range of functions, are more and more fully integrated into everyday life. Yet, they by-andlarge remain excluded from schools and core functions of school-based learning. Although media use in everyday life and school belong to separate cultural practices governed partly different structures and student/user agency, we posit here that it 
should be possible to consider mobile devices as learning resources. What, we ask, could be the educational motive to bridge this separation and these differences? In posing this question, we are not motivated by attempts to modernise the school or to instrumentalise it as vehicle for technological innovation of society, which was a motive in relation to the promotion of the internet for example. For us, there are at least two educational arguments at play here: one considering children and young people as societally integrated individuals, who have to learn to assemble divergent social and cultural realities, among them realities of everyday life and of traditional schooling. The task of integration, we argue here, can be supported educationally meaningfully by recognising the expertise students have by virtue of their everyday lives and attendant media practices as cultural resources inside the school and as meaningful for their traditional ways of learning. Such a line of argumentation requires for the agency and cultural practices of students, who live in a fragmented society of individualised risk, to be welcomed by schools.

Our second line of argument relates to the recent difficulties of schools to provide all young people with the knowledge, skills and understanding necessary for adequate participation in dominant cultural and societal practices. PISA-results (Programme for International Student Assessment ${ }^{1}$ ) indicate a failure of the school system in many industrial societies to integrate all social milieus. Therefore, mobile devices are understood by us as cultural resources, which relate to specific mass communicative structures and cultural practices. It is an educational task, we argue, for schools to investigate the potential of cultural resources outside school as learning resources within.

Let us make a preliminary remark on the introduction of the concept of icultural resources> here: to consider media as cultural resources, in our view, opens the argumentative door to an ecological view of the issues in question; it opens the discussion to a view of children and young people as subjects, i.e. as agents in cultural practices within social and mass communicative structures. It affords the option to consider the appropriation of media innovation by children within given structures and it enables an educational response by developing pedagogical practices with reference to the students' diverse cultural practices within incoherent social structures.

We use appropriation here following Cook, Pachler and Bradley (2008) who view it as a process of making the technological tools at one's disposal one's own by making them fit personal, interpersonal and social requirements, rather than using them necessarily only in accordance with designed-in functionalities and/ or accessorising them. Cook et al view appropriation as being characterised by user agency, as actions on tools and devices with users/learners actively making choices that relate to their practice. Thus agency by the user/learner underpins

1 http://www.pisa.oecd.org/pages/0,2987,en_32252351_32235731_1_1_1_1_1,00.html 
our notion of the process of appropriation, as a process of making technology one's own for purposes of identity formation, social interaction, meaning-making and entertainment. As we will see in our first case (Cyrill), the appropriation of mobile device can be the result of self-organised learning, reflection on ones own learning outcomes, and an interrelation of agency and practices to which learning, competences and assessment (including reflection) belong. Specifically with reference to the appropriation of the mobile phone, Cyrill acts within the structure of the ongoing transformation of mass communication in which the mobile phone possesses the most powerful dynamic.

The following section reports on a case study of a young man's provocative use of the video function of his mobile phone within the broader structure of media convergence. By media convergence we mean here that the subject uploads his «mobile video s on a media platform. The description of the case is followed by a theoretical frame, which attempts to combine the cultural practices evidenced by young people in the use of their mobile phones with learning as the predominant cultural practice of the school. We do so in an attempt to demonstrate how schoolbased learning can be adjusted by assimilating, i.e. integrating, the use of everyday practices relating to the use of mobile phones. This assimilative integration is based on the traditional bipolar view of learning which ranges from informal to 〈formal〉 (see Sefton-Green 2004, Cook, Smitt 2004, Soerensen et al. 2007), which, whilst in and of itself meriting closer examination in relation to its continued fitness for purpose would go beyond the cope of the current paper.

\section{A case study of provocative mobile video use in conjunction with a media platform: structures, agency and cultural practice}

This following short case study should be read as an example of a practical educational task which, we would argue, provides food for thought about whether and how school learning can and should be adjusted to take account of the cultural practices of a young man dislocated from society and formal education, but with a rather well developed expertise within the context of media convergence. Media convergence, we argue, is one important structure of ongoing cultural development and is driven by media institutions and media users (see Bachmair 2006a, 2006b, Wagner, Theunert 2006) on the basis of certain systemic structures (see Castells 2004). It is within structures of media convergence that the 18-year-old Cyrill developed his practice of using the mobile. The structure of an internet video platform (MySpace, YouTube) frames his way of taking and disseminating videos as does the local and regional context. Together with a group of young men he filmed drunken homeless males at a regional train station in Southern Germany and uploaded these short videos onto YouTube. Within this regional context the public prosecutor is now considering bringing criminal charges because of one video, which depicts the harassment of the homeless men. The behaviour evidenced in 
the video could be considered to be an offence against human dignity. Other videos contain Nazi symbols, which also makes Cyrill liable for public prosecution. Cyrill is German from a migrant family, probably from Turkey and $2^{\text {nd }}$ generation, which, we feel, is relevant for his media use. The case of Cyrill came to our attention through the regional newspaper where it was covered.

\section{The video}

Within a group of four peers, Cyrill took videos with his mobile phone at the regional train station of homeless drunken men, who were not in a position to give their consent to being videotaped. The still image below from Cyrill's video depicts a situation of harassment. Harassment is however not foregrounded in the video; instead it can be viewed as providing an observation on white drop-outs in German society. The intention of the video is probably to show who the real social underdogs are: in Cyril's and his peer group's view they are not young migrants. The main stance of the video arguably is to provide an observation on social situations, by way of a kind of unemotional description, which avoids personal feelings. We suspect that a sense of perceived superiority and a desire to exercise some control probably motivates the actions of the group.

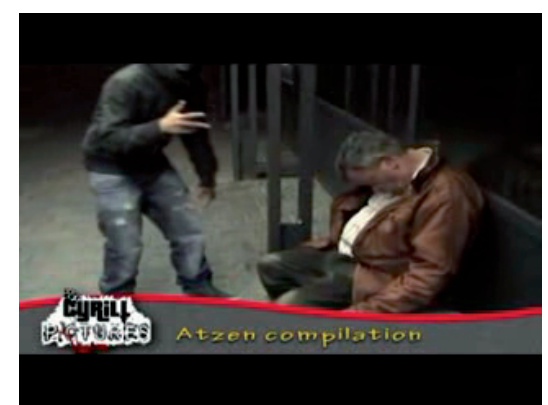

Picture 1: Extract of Cyrill's mobile video «Atzen compilation»

\section{Media and mass communicative structures and their relationship with the mobile phone}

The mass communication context, together with the personal motivation behind the production of the video and publishing it on a video platform, structures the act of communication and the final product. In relation to the mobile phone, Cyrill acts within the structures prescribed by the ongoing transformation of mass communication, in which the mobile phone carries a powerful dynamic. Within this structure Cyrill does not act as a so-called (trend setter) but on the basis of developed expertise. The ongoing transformation is characterised by the following characteristics:

- a move away from an editorial system towards archives such as media platforms, 
- a move away from a push to a pull system of media distribution,

- the use of the mobile phone with a variety of applications as ubiquitous personal media tool,

- user-generated contents and contexts,

- convergence with Web 2.0 tools of the internet,

- the structures of the internet media platforms YouTube and MySpace (see below for details).

These structural changes to mass communication also affect the agency of the user. Cyrill not only found a way to act within the new structures of mass communication, but he also developed himself into an expert. Theoretically speaking, he appropriated the new structures and used the mobile video application plus the convergence extension for his personal ends, i.e. to identify social outcasts (homeless drunks) and to contrast them with his self image using the internet as a media platform.

\section{Cyrill's media expertise with mobile video and on MySpace.com}

Cyrill's media expertise is grounded in the structural transformation of mass communication and he develops his expertise as a result of his cultural practices and his agency. In one of his web presentations he demonstrates his elaborate competence by putting several and divergent self images on a rotating cube superimposed over his picture.

Cyrill integrated the video into his personal site on YouTube and MySpace. He names his site on MySpace «cypictures», which to us signals a clear professional
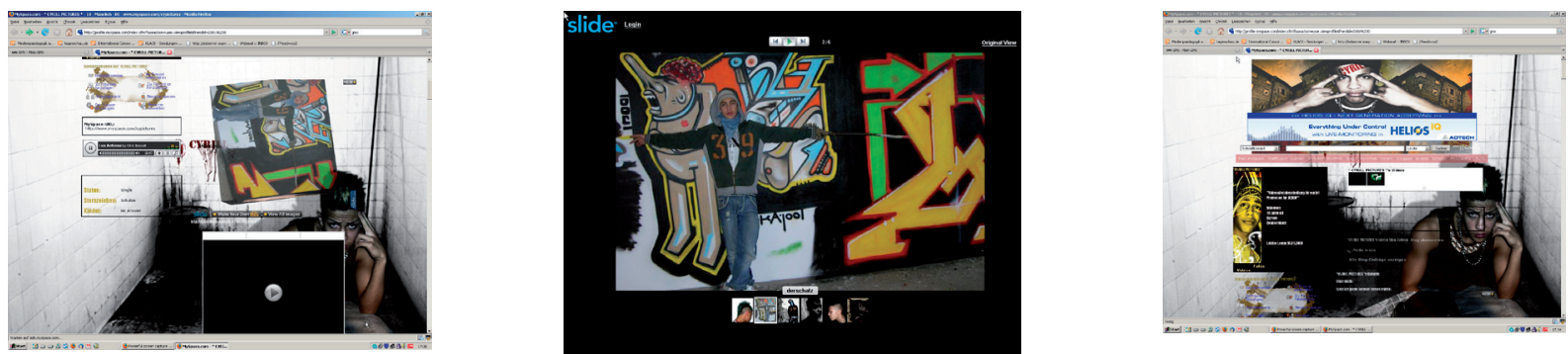

Pictures 2a, 2b, 2c: Cyrill's self images on an internet platform

touch. The prefix 〈cy〉 also gives him a personal identity by referring to the name he uses on the internet. His video also has a logo, ¿Cyril pictures〉, which implies a relationship to a professional institution and corresponds to the institutional offers and adverts on video internet sites. 

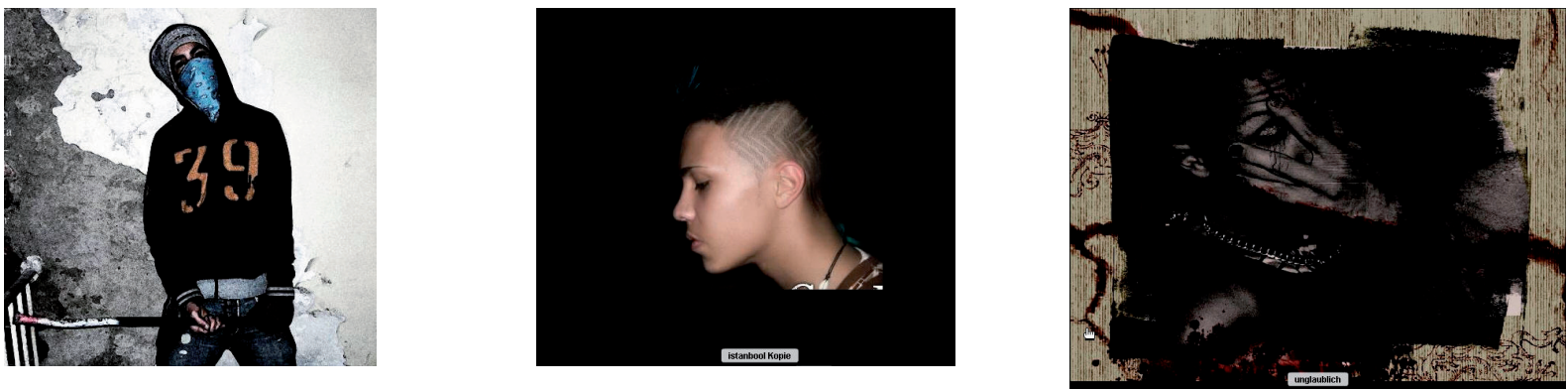

Pictures 3a, 3b, 3c: Cyrill's divergent self presentation: from violent, sensible to victimised

During the police investigation Cyrill deleted the incriminating videos as well as his site on YouTube and moved material inter alia to MySpace. On his site on MySpace Cyrill foregrounds the presentation of himself and he engages in followup communication with visitors to the site. He presents himself rather differently compared with the video about the homeless men, ranging from being hurt and vulnerable (picture on the left) to being a gang fighter (picture on the right). As we have already noted, the presentation by means of a rotating cube requires a detailed knowledge of specialist software. His practice around taking videos with his mobile phone and uploading them onto the internet is a result of his expertise, which turn is the result of learning processes that have taken place mainly outside school. Cyrill has also developed expertise within the structures of the video platform to which he links the video function of the mobile. This allows him to capture and share situationally contingent images.

This brief examination of Cyrill's combined use of a mobile phone and video platforms reveals what we describe here as expert patterns. Cyril himself stresses his highly developed expertise by choosing the label ‘cypictures〉. This expertise is a result of self-organised learning of which a certain level of self-reflection on his learning outcomes is an integral part.

The concept of the expert and expert patterns describe an interrelationship of agency and practices, to which learning, competences and assessment, including reflection, belong. In contrast to the concept of expertise, the concept of literacy contains beside agency and cultural structures also structures from mass communication. Media literacy, or mobile literacy, refers to a specific interrelationship of agency, structures and practices, e.g. the predominance of a medium like the book in school, or the predominance of TV, mobile phones and the internet in the everyday life of young people.

The structure of a video platform and the use of mobile video

Cyrill does not use the mobile video function for interactive purposes like a telephone call, but as a sub-tool of an internet platform. Internet-based media platforms foreground community functions such as participation and the 
relationship between online and offline dimensions. In addition, a video platform contains the following structural elements (see Elisabetta Adami's 2009).

- double media access (computer and Video/Mobile) with multimodal representation,

- communicative order mainly by way of written texts and conversational chains,

- international communication underpinned by common codes of global English and international culture,

- regional communication through video characterised by an amateur style which integrates the personal (thematic) perspective of the user coupled with global publication,

- priority of the representational modes above the communication content.

As we have mentioned already in the introduction, our socio-cultural ecology aims to understand cultural transformations as a result of socio-cultural structures, agency and cultural practices. Our educational motivation is to understand mobiles as appropriated resources for the user's interaction with the social and factual world. Cyrill appropriates this structure, for example by using the mobile phone, a computer and the internet for his communicative purposes. He combines them with regional communication: the main station of the city where he lives and discussions with the police. The follow-up communication is part of the communicative structure of the internet platform and it is positioned within a regional and global alignment. Whilst not narrowly evidencing Cyrill's expertise with mobile phones, the example shows that Cyrill is very much at home with the functionalities of video and social networking platforms. In addition to developing his practice within a given structure, Cyrill also aims to change the structure through his practice, through his agency, his mobile video and the way in which he presents himself on his website, which are ostensibly acts of provocation of mainstream society.

\section{MySpace: communicative order and the tension between global and regional poles}

Because of the specific regional cultural context, the police, the regional newspaper and an association concerned with protecting homeless people reacted to the online publication of Cyrill's video. Cyrill gets caught up in the complex interrelationship of global, mass cultural phenomena (in particular personal practices enabled by handheld devices interfacing with ubiquitous internet technologies) and the dominant regional culture and values which accept, and protect drunkards hanging around the station and their human dignity. Among other things, the case received considerable newspaper coverage. Urged by the police, Cyrill deleted the video in question as well as other material. But even without the video there remain 
some related postings on MySpace mainly in the form of personal questions and statements as well as advertising and links to professional institutions.

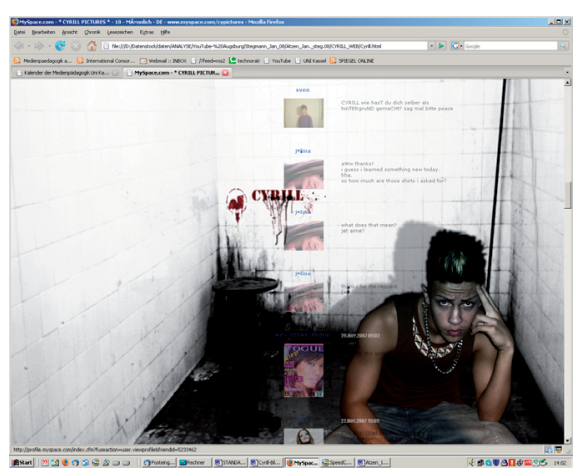

Picture 4: Cyrill as a software and web expert: screenshot of «CYRILL PICTURES» on MySpace (http://www.myspace.com/cypictures, Jan $9^{\text {th }}$ 2008)

Typical for the nature of the follow-up communication is the question to Cyrill by a boy, Sven (see picture 4, first lines), who addresses him as expert on websites. His question is framed by the website:

CYRILL wie hasT du dich selber als hinTERgruND gemaCHt? Sag mal bitte peace.

Translation: "Cyrill how did you make yourself as background? Say it please peace.

Svens's question is not typed orthographically correctly. He uses capital letters in violation of German language rules, which impedes intelligibility. The word speaces does not fit in, but is probably used in the context of youth culture.

Additionally a young man, who calls himself «eMKa) and obviously a peer of Cyrill's, takes part in what we call (the follow-up communications even if the online interaction doesn't necessarily directly relate to the digital video Cyrill had uploaded. He, too, does not refer to the video itself. Instead, he uses Cyril's web space to frame his personal reflection.

Geboren im Jahr 1982 in Augsburg aufgewachsen in Hochfeld und Pfersee wo ich auch in Kontackt zu Hip Hop kam. Mein Onkel damals Breaker im Pfersee Juze ca ende der 80er nahm mich After mit und er tanzte damals auf Rumors. Schon damals hab ich meine Eltern auf der Urlaubsfahrt ins 3000 km entfernte Heimatland TAxkei mit dem Lied genervt. Dann kam Kriss Kross mit Jump, Vanilla Ice mit ice ice baby, Mc Hammer mit Cant touch this und Public Enemy dazu. Seit dem Tag leb ich und Lieb ich die Heilige schwarze 
Musik. Seid einem Jahr mach ich nun aus Hobby Musik eher um abzuschalten und auf andere Gedanken zu kommen. Das Arbeiten im Schichtbetrieb mit Akkordzahlung und das Verheiratet sein sind sehr zeitaufwendig und daher eher selten am Mic aber ich geb mein bestes :D. Ja ka wer was wissen will einfach melden :P.

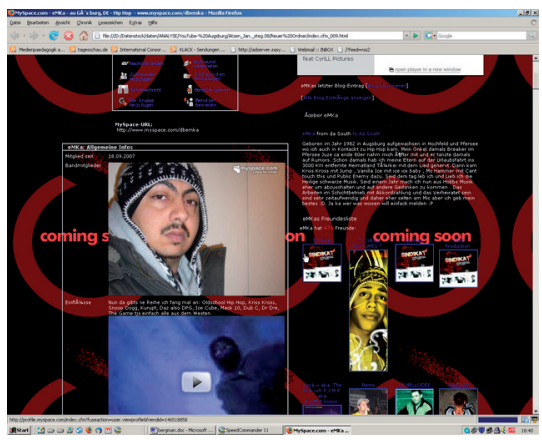

Picture 5: Screenshot of «CYRILL PICTURES» on MySpace with a written text by a hip-hop fan, his photo and a photo of Cyrill

eMKa writes about where he grew up: in two neighbourhoods of the same city in which Cyrill lives. There he came in contact with «Hip Hop through his uncle, who danced to (Rumors). He refers to playing his favourite song on a trip to Turkey and to later favourites: 〈Kriss Kross with Jump, Vanilla Ice with ice ice baby, Mc Hammer with Cant touch this and Public Enemys. He also writes that since that time he loves what he calls (Holy black music), a hobby which gives him an alternative to daily routines: it allows him to switch off and change his state of mind. He also notes that working shifts, being paid according to how many pieces he is able to produce, and being married are very time-consuming and impede his ability to DJ himself. The language used in this short text clearly does not follow standard German orthography, but at the same time it is also not written by someone who is unfamiliar with German vocabulary and grammar. Instead, some kind of new German dialect seems to be evolving here. The text is characterised by a reflexivity, which brings the author's life story or curriculum vitae in an interesting relationship with the songs or music groups of particular periods of his life. Music can be seen to provide structure and to add a meta-reflective richness to the author's curriculum vitae and the circumstances governing particular life episodes.

These postings on Cyrill»s website, we would argue, have considerable relevance for schools, which function on the basis of a model of literacy which was appropriated in, and promoted by the school. The postings on Cyrill's website are also a relevant in the context of convergence of mass communication and the role of mobile devices in them (cf. tools such as Twitter or Shozu). Apart from facilitating 
the ability to post to, and to read on the internet, the mobile, of course, offers other options for written communication such as text messaging. We view all these written verbal activities as potential levers to adjusting the linguistic practices of school-based learning and align them with the existing verbal competences in the context of current media-rich cultural practices of young men such as those we introduced above. The postings demonstrate ways to appropriate the pre-given media structures on the basis of formative agency by way of cultural practices that are visible, make use of media convergence and can be seen to be related to literacy practices prevalent in schools.

\section{The socio-cultural structures in which Cyrill is active}

Cyrill does not only act within structures of mass communication, which are far removed from the school, but also within socio-cultural structures, which are in conflict with the school and its typical scripts for learning. German society, like other European societies, is segmented into socio-cultural milieus, which are constructed within two dimensions: the dimension of the 'social status a and the dimension of «basic values». Social status comprises formal school education, profession and income. Stratification in this dimension corresponds more or less with layers of social class. Empirically verified social-cultural segmentation is available in the form of the SINUS-milieus.

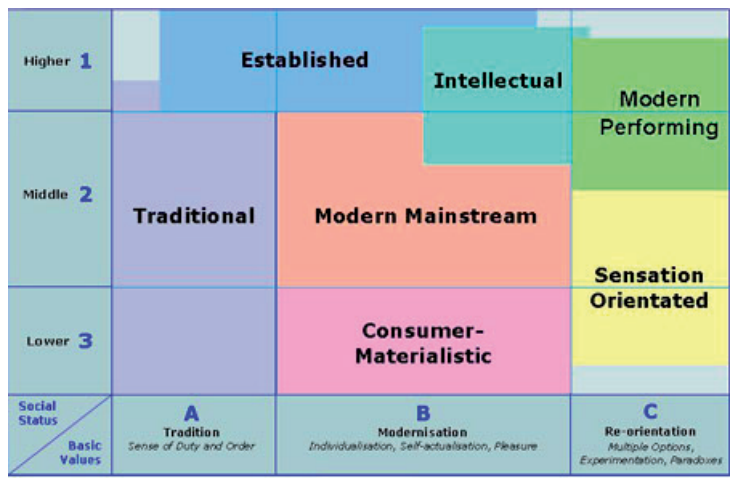

Picture 6: Sinus-Meta-Milieus ${ }^{\circ}$, http://www.sinus-sociovision.de/grafik/everyday-lifesegmente.jpg, 4. September 2007

It is very likely that the four boys of Cyrill's svideo groups have a migrant background within the socio-cultural milieu of the shedonistic subcultures using Sinus Sociovision terminology. As we have already noted above, this orientation leads in the case of Cyrill to self-portrayal as an underdog whilst at the same time conveying a certain sense of superiority. It is against this background that we interpret Cyrill's video about the homeless: as an attempt to look for the real underdog as well as, of 
course, to have fun, which is always important. This, we feel, is probably the sociocultural basis for the video on the homeless people at the station.

The Sinus Milieus offer the following description for the segment to which Cyrill probably belongs (Sinus Sociovision 2007a, 2007b):

The fun-oriented, modern lower class / lower-middle class (Escapists): Disregard for convention and behavioural expectations of the achievementoriented society. This milieu contains $11 \%$ of the German population. (http:// appz.sevenonemedia.de/download/sinusmilieus_04.pdf)

The basic orientation of the shedonistic-subcultural milieus (BC3, escapists) in the migration context (Sinus Sociovision 2007, p. 65) can be described as follows:

- against the background of the experience of exclusion (self image of being a (Kanak), which evidences an ethnic cultural reflexivity) on the one hand the dream of a rich life in Germany with easy money, luxury, prestige («Kohle scheffeln und Spass haben»); on the other hand resignation and a defiant uunderdog» mentality: being unemployed, without chances, discouraged;

- (partly aggressive) distance to the mainstream of society together with not being adjusted - for example, in the outfit, in behaviour and language -, conflicts with authority and authorities (parents, teachers, supervisor, police); on one hand disapproval of demands for integration and achievement, and on the other hand the desire for success, appreciation, a higher income and a better job;

- orientation towards the shere and nows, hardly any long term and future planning, uncontrolled spending of money, financial problems, often no perspective for the future («Null Bock»), insecurity, being passive.

\section{Towards a theoretical frame for the adjustment of school practices to the smobiles expertise and cultural practices of students}

Looking at the case of Cyrill, one cannot fail but notice that his use of one of the mobile phone's functions, namely the video function, is integrated in two main suprastructures: media convergence and social-cultural stratification. Cyrill displays noticeable expertise to act purposefully within these structures; for example, he displays considerable software competence and engages in written communication online. These complex literacy practices motivated by competent use of the mobile phone as phenomena of everyday life are separate from school, yet schooling contributes competences, such as the ability to read and write, to them. At the moment, and from the perspective of the school, this segregation is intentional. Most schools still ban mobile phones. Although Cyrill does not have the intention to align his expertise with that of the school, nevertheless the competences he evidences would appear to be at least in part compatible with 
those relating to formal schooling. Looking on video platforms, for example, a lot of homework activities can be found that have been produced with and for mobile phones (see e.g. http://de.youtube.com/group/MathTutor and below). These examples clearly indicate to us that the prevalent segregation of the practices Cyrill engages in and the institutional practices of schools are compatible with each other and need not be kept apart.

To overcome this separation, which is maintained by schools and students, our proposal is to adjust the practices of schools to be more open to the practices around mobile phone use, incl. the agency and structures which became visible in our description and analysis of the case of Cyrill. However, we wish to sound a word of caution and want to avoid the inherent dangers of an educational Scylla, i.e. the exploitation of the cultural practice of students in order to achieve greater effectiveness of learning as well as the opposite, Charybdis, i.e. to functionalise the school with a view to bringing about technical modernisation of society. What could be the educational alternative we ask? Our proposal is to consider mobile phones and other comparable mobile devices as cultural resources, which belong to everyday life as well as to school.

\section{Cultural resources}

The first pedagogical step is to consider media, knowledge and learning as cultural resources within the interrelated triangle of structures (e.g. application of mobile devices, mobile phone as tool of convergence), agency (e.g. application of media) and cultural practices (e.g. learning within the school, media use in everyday life). With reference to the natural scientific notion of ecology, a cultural ecology, which we suggest here, asks first of all, what is transformed into a resource. The question about resources intends to unveil the function of cultural resources in individual lifeworlds and in society. The span of cultural resources reaches from language, media or knowledge and includes time and space. With respect to the actual transformation of mass communication and the school, which is an issue of importance to us, two resources are of high relevance:

- mobile media especially smartphones,

- knowledge as relevant cultural practices and cultural objects within the processes of globalisation.

As we have already noted, cultural resources are integrated into a system of structures, agency and cultural practices. We argue that it is important to deal with the questions in hand in an ecological way; a way which supports and protects the potentially overwhelmed and exploited actors and their cultural practices. Attendant is a pedagogic turn away from power towards a specificity of media use and learning. We refer to such a critical educational stance as a ccultural ecologicalı approach (see Gibson, Pick 2000). It can, and should, be viewed as an 
attempt to avoid the instrumentalisation and exploitation of communicative culture and practices as resource for consumption and power. We would also stress that cultural processes and objects such as knowledge, learning and new media should be viewed as functional resources within power structures. How do we determine what it means to functionalise or instrumentalise in educational contexts? The main pursuit for us has to be the development of children to self-determined and social human beings.

\section{Meaning-making in culturally defined situations}

Also integral to our way of thinking is the need to identify media use and learning as meaning-making in culturally defined situations. Therefore, our ecological approach to the use of, and learning with mobile devices is based on meaningmaking. Constituent for meaning-making are situations (see Hanks 1990), which are culturally defined and which differ in terms of cultural development. School learning takes place in a specific cultural context. Hence, we see school learning as meaning-making in a culturally specific environment, based on specific teaching and learning paradigms, which - for numerous reasons - are currently in transition. Teacher-centred approaches to learning are still not only accepted in the context of school in the industrial societies, in fact they are more or less taken for granted despite many prevailing theoretical educational discourses opposing or at least questioning them. In addition, a second paradigm prevails, namely the separation of mass media, as part of the entertainment sector, from school learning. Given our view of the use and appropriation of mobile media as well as school learning as meaning-making, albeit in very different cultural situations, both paradigms require revision.

We posit that the processes of meaning-making in culturally defined situations with mobile devices should be viewed in the context of the interplay between structure, agency and cultural practices. With reference to Anthony Giddens' view of the relationship of structure and agency (1984) in educational and media contexts, we view agency mainly as appropriation. Cultural practices in the context of media (e.g. Stuart Hall 1980, 1997. p. 36) are more or less stable results of meaningful activities related to social and cultural structures.

\section{Educationally relevant features of structure, agency and cultural practices}

Which features of structure, agency and cultural situations relevant to education are in the foreground of the cultural ecologic approach to mobile learning?

- Structures: media convergence, applications of mobile media; media literacy

- Agency: appropriation as internalisation and externalisation with regard to learning and media use in everyday life; prevalent learning habitus in personalised lifeworlds 
- Cultural practices: learning outside the school (informal learning) with media; learning and teaching inside the school (formal learning).

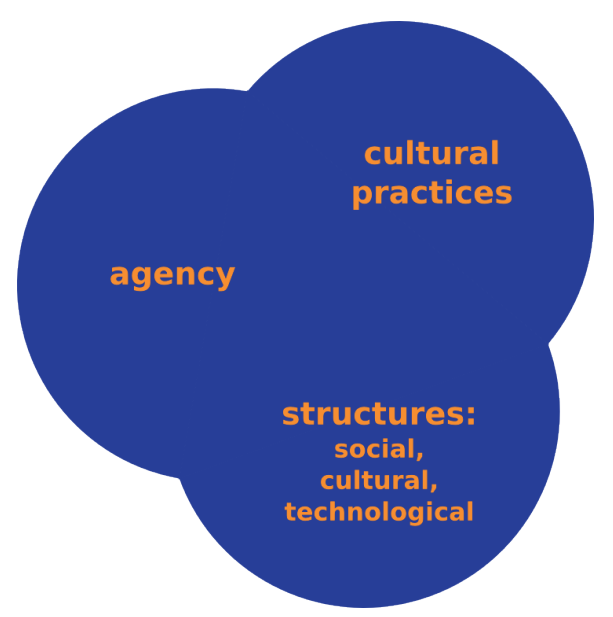

Picture 7: Key components of a cultural ecological approach to mobile learning

One relevant educational question relates to media literacy as basis for cultural participation. Media literacy is mainly viewed as the cultural practices of children and young people as well as a vehicle for and articulation of their agency within social and mass communicative structures. An important question relates to the contribution of mobile devices to learning in terms of using and developing knowledge. There is insufficient space here to go beyond raising these questions:

- What kind of knowledge and learning is potentially inherent in the cultural practices of the mobile phone and the attendant structures of mass communication?

- What kind of new learning habitus in the differently constructed personal lifeworlds and socio-cultural milieus correlates with, and are linked to these media practices?

As already stated, media practices - like all other cultural practices - are processes of meaning-making. Learning is also meaning-making but always within culturally specific formal and/or informal structures and a specific habitus. In school-based learning environments the contribution of mobile devices is often restricted to motivational factors; they tend not to be viewed as a defining and integral part of a successful learning design. Interpreting teaching and learning as conversational discourses (see Laurillard 2002, 2007), it is possible to set up curricular conversational chains, e.g. by organising follow-up communication to mass media practices. Combining informal learning outside the school with informal learning inside the school on the basis of the potential of mobile devices in relation to knowledge creation and management within non-editorial and convergent mass 
communication must be linked to a critical examination of inherent literacies, examined in relation to potential conflicts with established school structures and processes in this regard and in relation to questions of students as learning agents as well as active participants in the new structures of mass communication.

\section{Learning situations enabled by mobile devices: assimilating students' expertise from everyday life into formal learning}

Put simply, educational activity should be focused on supporting the agency and practices of children and young people as meaning-making. A prerequisite for that is for schools to engage positively with the mobile phone and its variety of functions as cultural resources. As a first step schools need to review their policies of banning mobile phones; instead, ways should be sought to assimilate students' expertise with the functions of mobile phones. Assimilation includes the design of learning opportunities and activities that integrate the cultural practices of everyday life of young people like Cyrill into school structures and prevalent educational scripts. We consider this proposal to have particular potential and currency because of the situated character of appropriation of mobile devices and formal learning as meaning-making. The case of Cyrill shows that his expertise is well developed and embedded in social situations, for example using the internet for taking a communicative stance or exchanging views in writing with peers. His provocative attitude portraying himself as unfairly and inappropriately treated, i.e. as an underdog, represents a big barrier to school if school remains determined to teach him traditional curricular subjects in traditional ways. We suspect that public mis-èn-scene and involvement within the school context, for example as software expert or blog expert for peers will probably attract him. In the context of the Mathematics curriculum, one could, for example, think about the possibility of creating a maths «microworld for the class or the school. Ideas how to do this can, for example, be found on homework websites for maths using mobile phones (see below). The example of field research of an Indian school also discussed below provides additional interesting curricular ideas but requires an adjustment of traditional pedagogy to the learning habitus of students such as Cyrill.
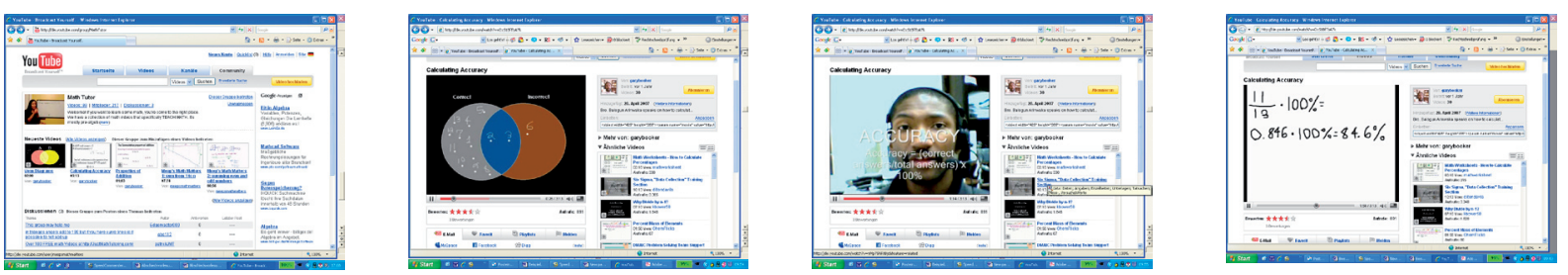

Picture 9a, 9b, 9c, 9d: videos for math «Calculating Accuracy» on a media platform http://de.youtube.com/ group/MathTutor, May $16^{\text {th }} 2008$ http://de.youtube.com/watch?v=DxS1BfTbA7k, May 30 2008 


\section{«Mobile〉 Homework}

In a Swiss elite school in the context of a homework task for the subject French, a pair of students focused on the structure of the 〈passé composes. They produced a video with the mobile phone through which the structure of the spassé compose is visualised. In parallel, one student verbalises this structure. The teacher uploaded the video onto the school's website. (Rolf Deubelbeiss was the responsible teacher and headmaster of the «Nationale Elitesportschule Thurgau», Swiss, reports http:// klippundklar.blog.de, Feb. 29th 2008.) We classify this example as «mobiles homework as we see the concept of mobility located within the mass media structure of convergence. Students upload homework, which has been composed with the help of tools such as the digital video function of their phone which are combined with social networking tools. Like the board in the classroom, the social network space functions as a kind of public sphere, albeit of a different order of magnitude.
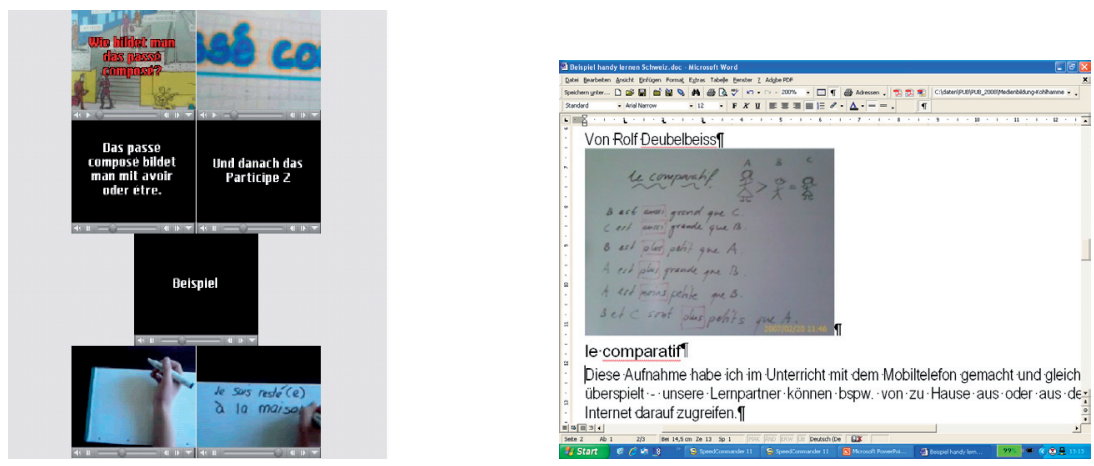

Pictures 8a, 8b: Screenshots of a mobile video on a school website, http://metaportfoliophsg.kaywa.ch/franzoesisch/passe-compose-yannick-2-real.html; http://metaportfoliophsg.kaywa.ch/franzoesisch/le-comparatif-s2.html, Feb 29th 2008

In this context, the mobile phone provides the opportunity to generate content and contexts. Traditional learning task can be enhanced by producing subject-related content and by supplementing situations for learning, i.e. widening traditional contexts. The screenshot below (Picture 9a-9d) of MathTutor on YouTube serves as an example here. The community area of MathTutor, for example, features a video on «Calculating Accuracy). The video to the extracts below is a mixture of a micro lecture (see Hug et al. 2006) plus a sketchbook for taking notes and work on these notes. 
The video below (picture 10a, 10b) «ZOPStudios - Math Tutor» tells the story of how access maths by working cooperatively.
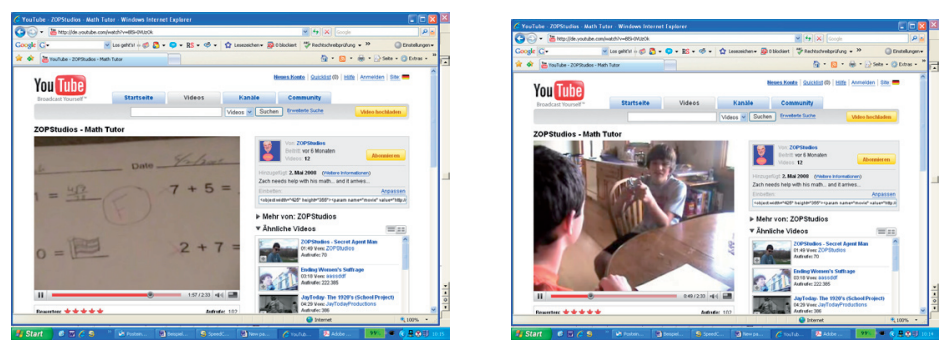

Picture 10a, 10b: «ZOPStudios - Math Tutor» http://de.youtube.com/ results?search query=math+tutor\&search_type $=\& a q=0 \& o q=$ math + tu, May $30^{\text {th }} 2008$

This is an example of collaborative learning at home doing homework for the school. The video is presented as a story of two students meeting at home and being worried about their maths: "Zach needs help with math». The viewer is offered a look into the sketchbook, which serves as basis for cooperative work. The leading media is the mobile phone with its video application which is brought into a mathematics orientated community on the internet. The mobile video stretches and combines the school context, the home and an internet platform and helps to set up an individualised mobile context, which is targeted for learning. For this sort of context generation mass communicative structures are decisive but as are the agency of the user / learners and traditional and newly emerging cultural practices of learning (school, Math community).

\section{Field research as part of the school curriculum}

In one Indian school, the Domlur Goverment School, Indiranagar, Bangalore, mobile phones, together with a computer, were used to open the curriculum to new approaches to teaching and learning, away from teacher-centred learning with text books and memorisation towards a more cooperative, self-organised learning by students including field work outside the school. In geometry and biology students went outside the school building to find relevant material, e.g. geometrical forms or plants, capturing them on mobile phones and bringing them back into the classroom (Center for Knowledge Societies 2005, without year/ accessed Feb. 28 ${ }^{\text {th }}$ 2008) 

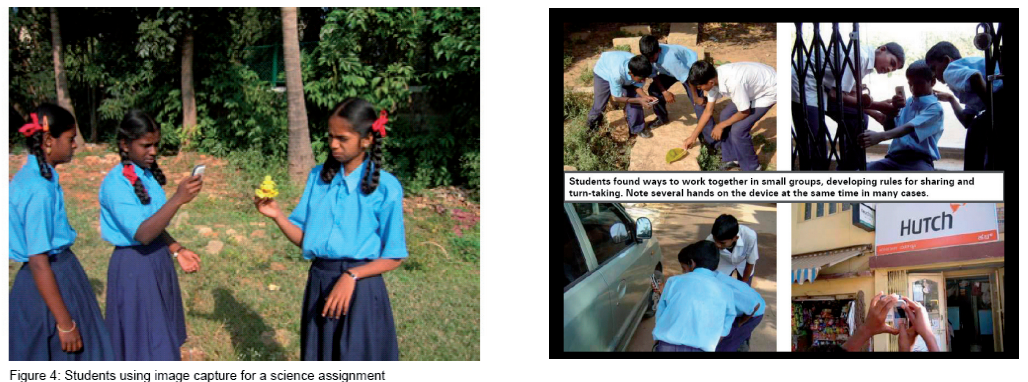

Pictures 11a \& b: Boys and girls are investigating geometrical forms and plants of everyday life outside the Domlur Goverment School (Picture 11a: Center for Knowledge Societies (without year - 2008) p. 26; Picture 11 b: Center for Knowledge Societies 2005, p. 7)

Students were also asked to use the GPS function of the mobile on their way from home to school and to produce a map charting their way. In addition they were asked to take photos at home. Afterwards the teacher worked with the material the students brought into the school during lesson time having stored it on a school computer. In geometry, a discussion on geometrical forms such as circles, balls, or cubes and trapezes was based around the pictures students had taken and a map was produced with the photos the students had taken. This is a convincing reference to reflexive context awareness. As the report (Center for Knowledge Societies 2005, p. 11) notes, these «exercises helped students develop a highly personalized and individualistic understanding of spaces around them». The production of the GPS data and the photos of the walking tour for the poster gave the students the opportunity to reflect on the context through which they walk, which they investigated by taking photos augmented by GPS.

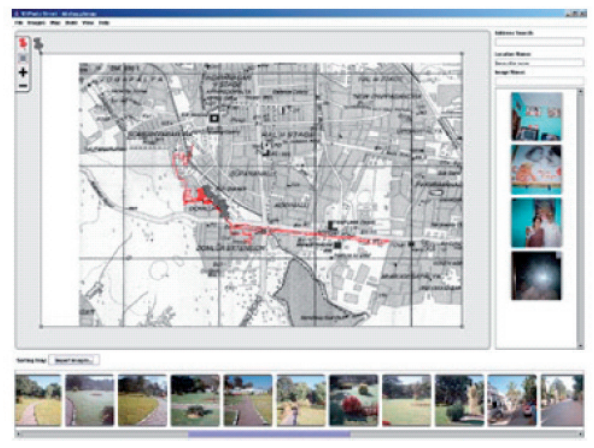

Figure 9: An example of an affective map layered with GPS track data

These exercises helped students develop a highly personalized and individualistic understanding of spaces around them.

Picture 11: A document produced with convergent means: mobile GPS and photo application as well as the PC for producing a poster (Center for Knowledge Societies 2005, p 11) 


\section{Accommodation and assimilation of informal and formal learning in relation to discourses}

The examples above relate to our theoretical arguments in the context of desirable curricular approaches for students such as Cyrill in at least the following two ways:

- media use and learning are culturally situated but on the basis of different structures, agency and cultural practices; and

- meaning-making in school situations has to be extended to cultural practices outside the school.

The task, then, is to find curricular ways of extending the cultural practices of schools and bringing them into a fruitful relationship with Cyrill's media practices. We consider references to Jean Piaget's (1955) thinking on learning and perception to be helpful in adjusting the culturally differently situated meaning-making of Cyrill as a user of a mobile phone and as a student in school. Piaget explained learning and perception as appropriation by two modes, namely assimilation and adaptation. Assimilation means that a child takes something unknown into his/ her cognitive structures. A child can also adjust his or her cognitive structure to unknown facts or events. The latter, adjusting cognitive structures to a new reality, Piaget calls accommodation. This dual way of adjustment is helpful in describing activities of the school and its agents, i.e. teachers and students, to react to mobile devices as genuine part of everyday life and mass communication. The analogue dynamic for mobile learning relates to the interrelationship between school and everyday life. The relationship between these discourses can be discovered by looking for typical structures of the use of mobile devices in everyday life and as convergent media tool within mass communication on the one hand and by looking for curricular school structures on the other.

Cook, Pachler and Bradley (2008) draw on the above concepts to define appropriation as «exploration, accommodation, assimilation and change for and in context-governed meaning-making with users/learners negotiating and evolving practices and meanings in their interaction with other users/learners, technologies and information.» Piaget takes us part of the way with his articulation of cognitive structures and knowledge. However, a key notion in this definition of appropriation is that users/learners are «evolving practices and meanings in their interaction». In Cyrill's case, the evolving practice was engendered through interaction on discussion lists with fellow (underdogs) via the internet, as well as with his environment, the police and so on. In this case of the Bangalore students, their evolving practice, and hence appropriation of the mobile devices, can be seen as emanating from interactions with family and other members of their offsite social groups, their environment as they walked about, and the community on-site within school, etc. 
The analytical categories of informal and formal learning as well of mobile media have to be adjusted to the discourses prevalent in schools (see Diana Laurillard's Conversational Framework 2002, 2007) and, especially, to the cultural practices of children and young people:

- their everyday life literacy practices including their representational modes and preferred media as a part of the appropriation of the practices attendant to mobile devices; and

- the changing structures of mass communication in relation to social cultural stratification etc.

The example from outside the school here is Cyril's use of mobile video and (in conjunction with) internet platforms. The curricular challenge is bringing Cyrill and his expertise into the scope of formal school learning by finding ways of bridging the gap between formal and informal learning (see Cook, Smith 2004, Sefton-Green 2004). Viewed from the perspective of the Conversational Framework, learning inside and outside school (informal and formal learning) can be seen as related discourses. Essential to these discourses are concepts such as the teacher and the students, the activities and curricular environments constructed by the teacher as well as students' learning strategies. In the case of non-curricular media practices, the school has to open its concept of learning to these media practices by trying to accept them in relation to existing curricular environments and learning strategies. In the light of Laurillard's categories (see below), the appropriation of mobile devices within in everyday life practices and relevant structures (what Laurillard calls «the world of experience», 2007, p. 171) has to be assimilated with reference to the learner's goals, his/her actions, feedback and revision.

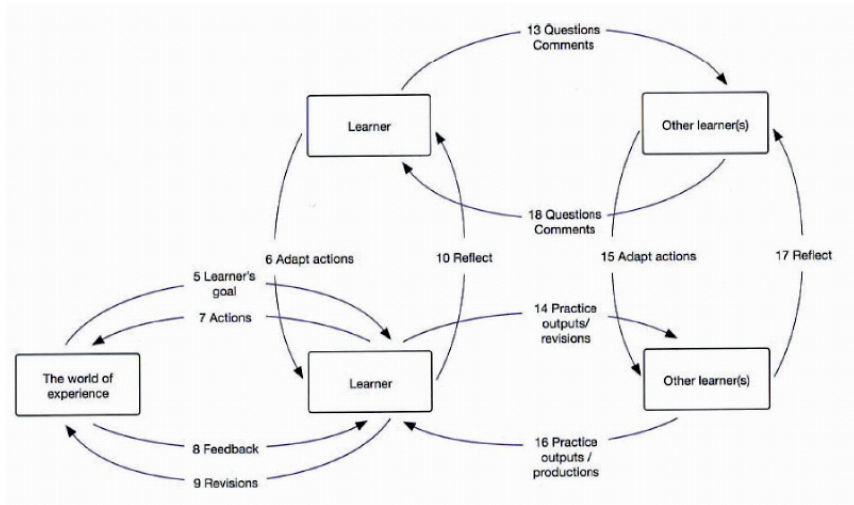

Picture 12: Assimilation of formal and informal learning in the perspective of the Conversational Framework (Laurillard 2007, p. 171) 
Laurillard's scheme (2007, p. 171) shows how the school can assimilate social media practices (what Laurillard calls «the world of experience»). The school gains access to the outside world through the students' goals, action, feedback, revisions and products. This comprises instructional, learning and everyday life strategies such as setting goals, actions, feedback and revision. The above example of the field research shows how applications and functions of the mobile phone incl. mobility, individual availability, taking photos, orientation in the geographic space (GPS), connectivity to computers etc. are constitutive elements of learning and also functional parts of everyday life.

\section{Three curricular dimensions as tools for planning or analysis of educational practices}

Learning inside and outside school (informal and formal learning) are seen as related discourses, which can be integrated on the basis of three curricular dimensions: media features; teacher's and students' discourses inside and outside the school; overall educational and curricular discourse (didactic discourse).

\section{(1) Media features}

In the above discussion the photo and video application of mobile devices, computer hard discs and the internet viewed from within structures and practices of mass media were considered for assimilative purposes. Through ongoing projects implementing mobile phones and other mobile devices into the school new curricular conceptual systems are emerging. An early example comes from Patten et al. (2006), who discuss media features already in curricular terms within «existing learning scenarios» (pp. 296 ff.):

- administrative: e.g. calendar or organiser on the students' mobile phone;

- referential: to store, access and annotate documents; information management and content delivery;

- interactive: e.g. a user responds to a task or receives feedback; 〈drill and test〉 with multiple choice style quizzes; to create own simple animation;

- microworld: allows learners «to construct ... own knowledge through experimentation in constrained models of real world domains» (p. 298), e.g. exploring simple geometric concepts within the context of a billiards game;

- data collection: to record data and information and create learning experiences that would not otherwise be feasible or unproblematic; e.g. note taking, on-thespot analysis, recording of images or sound for observations and reflection;

- location awareness: to "contextualise learning activities by enabling the learners to interact appropriately with their environment» (p. 299); e.g. museum guides;

- collaborative: to share knowledge and create a learning environment «inspired by collaborative learning principles» (p. 299); e.g. using learning platforms. 
(2) Description of the teacher's and students' discourses in the categories of the conversational model

As discussed earlier, the interactive, communicate, interpretative and productive relationships of teachers and students as evidenced in their major cultural practices and on the basis of their competencies have to be matched with the functionalities of mobile applications.

(3) Overall educational and curricular discourse (didactic discourse)

The leading educational and curricular discourses within models, such as situated or constructivist learning, provide a frame for considering school-based discourses and they provide, as well as close access to media-related and social structures, agency and cultural practices. Key concepts, such as collaborative, constructivist or situated, foreground the connection of context and learning (see Sharples et al 2007 , p. 230). Viewed in this way, we argue, mobile learning is not one approach to teaching and learning besides others; instead it permeates all approaches. As Sharples et al. (2007; p 223) stress, a «central concern must be to understand how people artfully engage with their surroundings to create impromptu sites of learning». Further reasons for technologically supported mobile learning can be found in socio-constructivist approaches to teaching and learning (Sharples et al. 2007, p 223), which put the learner and his or her appropriation of knowledge at the centre of school discourses. Appropriation by learners is collaboratively framed and «community-centred» (Sharples et al 2007; 223). Scardamalia and Bereiter (1999) concretise the collaborative frame of appropriation as «collaborative knowledge building:: "The job of an elementary school class that adopts a knowledge-building approach is to construct an understanding of the world as the students know it» (Scardamalia, Bereiter 1999, p. 278).

The structure of collaborative knowledge building includes the following:

- learning is not targeted towards presentable products, but to the development of common knowledge within the group of learners;

- students learn through their contributions to solving a problem; and

- learning is not targeted towards practical and usable parts of a problem and its solution, but towards the knowledge which is relevant for the solving the problem.

The three curricular dimensions:

- media features,

- teacher's and students' discourses inside and outside the school, and

- overall educational and curricular discourse

are helpful to describe the examples of the field research in the Indian school with a structure-orientated curriculum for maths: 
(1) Media feature: photo and GPS functionality of the mobile phone; computer hard disc

(2) Description of the teacher's and students' discourses in the categories of the conversational model:

¿Field research`combines culturally different situations, practices and representation in everyday life and school; penetration of cultural practices; cultural practices as discourses are situated in structures and literacy; the hand-drawn map and the GPS map plus photos taken with the mobile phone show the combination; the mobile as bridge between school and everyday life, penetration of youth culture and GPS-map.
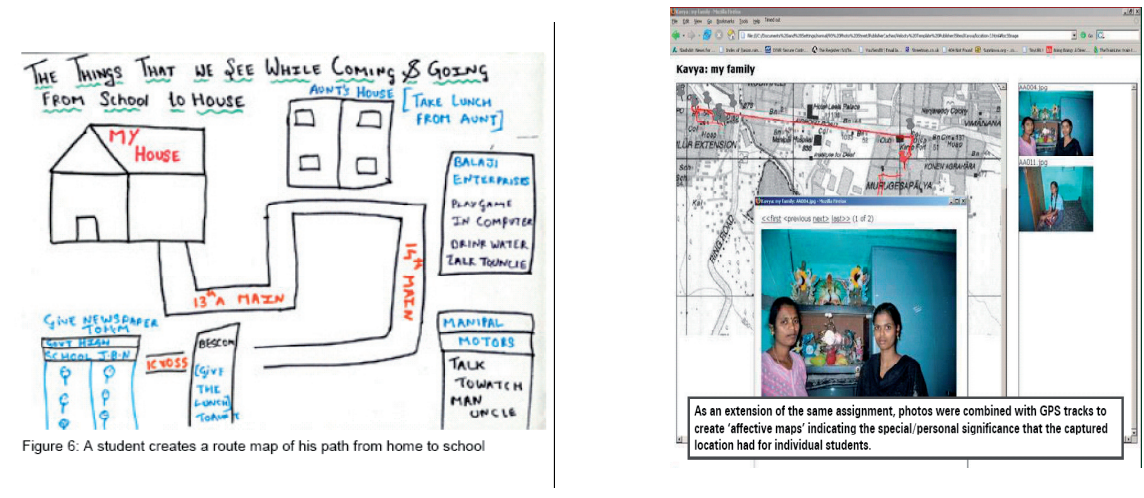

Pictures 13a\&b: Investigating the way home from school: still images and GPS on mobile phones, an example reflecting cultural practices (Picture 13a: Center for Knowledge Societies 2005, p 9; Picture 13b: Center for Knowledge Societies without year/ 2008, p. 29)

The field research for maths with the mobile phone's photo function leads to the penetration of the structure-based mathematics curriculum and everyday life and creates new learning contexts which are very close to the school as well as to everyday life (see picture 11a).

(3) Overall educational and curricular discourse: collaborative knowledge building on the basis of the mobile phone and other technological devices enhances instruction. The creation of contexts through collaborative knowledge building is obvious and rather close to everyday life forms of media-related interaction. Media convergence opens the located interaction to virtual cooperation, which is essential e.g. for Cyrill's use of the mobile phone together with the video platform of the internet (see also pictures 10a and 11b). 


\section{Conclusion and outlook}

The two very different case studies examined in this paper, and their associated analyses, were presented as learning activities that take place outside of school, but which could be assimilated or accommodated by and in school-based learning. The analysis leads us to propose three curricular dimensions as a means of conceptualising teaching and learning practices that make use of emerging technologies, these are: media features; teacher's and students' discourses inside and outside the school; overall educational and curricular discourse.

What we are not suggesting in this paper is that schools should restructure in order to meet these new cultural practices that can be found outside the school gates. Instead, we propose that schools should recognise and embrace this change and that recognising how mobile devices can be appropriated can help them adapt their own teaching practices in order to accommodate and assimilate these emerging cultural practices. Clearly, such a perspective changes the conceptions of where the boundaries of education are positioned. Other strategies for meeting these emerging patterns of cultural practice have been put forward for example by Haythornthwaite (2008), who has looked at the changing relationships in who learns from whom. When we learn, we are increasingly depending on online sources and the hidden work of retrieval algorithms etc (e.g. such as those used by Google). Haythornthwaite argues that this increases the work of the learner, and raises the need not only for critical media literacy, but also critical retrieval and retrieval technology literacy. However, this criticality is often not a primary concern when users share personal data on social networking sites such as MySpace and YouTube. Schools are perfectly positioned to embrace aspects of these emerging cultural practices and provide their students with $21^{\text {st }}$ century «literacy skills that enable them to engage with emerging and future digitally enhanced social networks and resources.

\section{References}

Adami, Elisabetta (2009): «Do YouTube?When Communication Turns into Video Enteraction.» In: Toretta, D.: Forms of Migration - Migrations of Forms. Atti del XXIII Convegno Nazonale A/A. Bari (Progedit)

Bachmair, Ben (2006a). "Communicative Modes after the Coherent Media - Orientation within a semiotic space.» MedienPädagogik 10.5.2006 www.medienpaed.com/2006/ bachmair0605.pdf ISSN 1424-3636

Bachmair, Ben (2006b). «Media socialisation and the culturally dominant mode of representation - On the way from the coherent media to semiotic spaces, the example of Popstars.» MedienPädagogik 7.6.2006. www.medienpaed.com/2006/bachmair0606.pdf. ISSN 1424-3636

Beale, Russel (2007). «Ubiquitous learning or learning how to learn and you'll never have to learn anything again.»In: Arnedillo-Sánchez, Inmaculada; Sharples, Mike; Vavoula, 
Giasemi (eds.). Beyond Mobile Learning Workshop. The CSCL Alpine Rendez-Vous Kaleidoscope Mobile Learning SIG, pp 64-65

Castells, Manuel (2004). The Network Society. A Cross-Cultural Perspective. Cheltenham: Elgar.

Center for Knowledge Societies, CKS (2005). «Learning Lab: Inclusive Education using Mobile Devices.» Paper presented on the International conference on inclusive design Royal College of Art, London, UK, 5-8 April 2005. Available from www.hhc.rca.ac.uk/ archive/hhrc/programmes/include/2005/proceedings/pdf/soodadityadev.pdf Accessed: February $28^{\text {th }} 2008$

Center for Knowledge Societies, CKS (without year, accessed 2008): «Learning Lab Initiative.» Project report. Available from http://www.cks.in/html/cks_pdfs/learninglab_ppt.pdf,. Accessed: Feb $28^{\text {th }} 2008$

Cook, John; Pachler, Norbert; Bradley, Claire (2008). «Appropriation of mobile phones for learning.» mLearn 2008, Telford, Shropshire, UK, 8-10 October

Cook, John; Smith, Matt (2004). «Beyond formal learning: Informal community eLearning.» Computer Education 43, 35-47. (Elsevier Ltd) Available online at www.sciencedirect. com

Eriksen, Thomas Hylland (2007). «Globalization. The Key Concepts.» Oxford, New York: Berg

Gibson, Eleanor J., Pick, Anne D. (2000). An Ecological Approach to Perceptual Learning and Development. Oxford University Press (OUP)

Giddens, Anthony (1984). The Constitution of Society: Outline of the Theory of Structuration. University of California Press

Hanks, William F. (1990). «Foreword.»In: Lave, Jean, Wenger, Etienne: Situated learning: Legitimate peripheral participation. Cambridge: Cambridge University Press. pp 13-24

Haythornthwaite, Caroline (2008). «Ubiquitous Transformations.» In: Proceedings of the $6^{\text {th }}$ International Conference on Networked Learning, pp 598-605, Networked Learning, Halkidiki, Greece. http://www.networkedlearningconference.org.uk/abstracts/PDFs/ Haythornthwaite_598-605.pdf, accessed August 2008

van't Hooft, Mark (2008). «Mobile, wireless, connected Information clouds and learning.» In: Becta Research Report, volume 3 «Emerging technologies for learning»

Hall, Stuart (1980). «Encodung/ Decoding.»In: Hall, Stuart et al. (eds.) Culture, Media, Language. Working papers in cultural studies, 1972-1979. London: Hutchinson. pp 128-139.

Hall, Stuart (ed.) (1997). Representation. Cultural Representations and Signifying Practices. London: Sage

Hug, Theo; Lindner, Martin; Bruck, Peter A. (eds.) (2006). Microlearning: Emerging Concepts, Practices and Technologies after e-Learning. Proceedings of Microlearning 2005. Learning \& Working in New Media. Innsbruck University Press

Laurillard, Diana (2002). Rethinking University Teaching: A conversational framework for the effective use of learning technologies. $2^{\text {nd }}$ ed. London: Routledge

Laurillard, Diana (2007). «Pedagogical forms for mobile learning: framing research questions.» In: Pachler, Norbert (2007). (ed.): Mobile Learning. Towards a Research Agenda. Occasional Papers in Work-based Learning. London: WLE Centre. pp 153-175

Nyiri, Kristof (2002). "Towards a Philosophy of M-Learning.» Presented at the IEEE International Workshop on Wireless and Mobile Technologies in Education (WMTE 2002), August 29-30, 2002 
Patten, Bryan; Arnedillo-Sánchez, Inmaculada; Tangney, Brendan (2006). «Designing collaborative, constructionist and contextual applications for handheld devices: Virtual Learning?» Computers \& Education, 46 (3), p. 294-308

Piaget, Jean (1955). The Child's Construction of Reality. London: Routledge and Kegan Paul

Scardamalia, Marlene; Bereiter, Carl (1999). «Schools as Knowledge-Building Organizations.» In: Keating, D. and Hertzman, C. (1999) (eds.): Today's children, tomorrow's society: The developmental health and wealth of nations. New York: Guilford. p. 274-289

Sharples, Mike; Taylor, Josie; Vavoula, Giasemi (2007). "A theory of learning for the mobile age.» In: The Sage Handbook of E-learning Research. London: Sage. pp 221-247

Sefton-Green, Julian (2004). «Literature Review in Informal Learning with Technology Outside School.» Futurelab Series, Report 7. Accessed at http://www.futurelab.org.uk/resources/ documents/lit_reviews/Informal_Learning_Review.pdf

Sinus Sociovision (2007a) «Die Milieus der Menschen mit Migrationshintergrund in Deutschland. Eine qualitative Untersuchung von Sinus Sociovision. Auszug aus dem Forschungsbericht.» Sinus. Heidelberg, 16. Oktober 2007

Sinus Sociovision (2007b). «Die Sinus-Milieus $® 2007$. Kurzcharakteristik Informationen zu den Sinus-Milieus 2007.» Stand: 01/2007 Internet: http://www.sinus-sociovision.de

Soerensen, Birgitte Holm; Oluf Danielsen, Janni Nielsen (2007). «Children's informal learning in the context of schools of the knowledge society.» IEduc Inf Technology 12, pp 17-27

Stald, Gitte (2007). «Mobile identity: youth, identity, and mobile communication media.» In: Youth, Identity, and Digital Media, MIT Press, ISBN 026252483X

Wagner, Ulrike, Theunert, Helga (eds) (2006). Neue Wege durch die konvergente Medienwelt. Studie im Auftrag der Bayerischen Landesanstalt für neue Medien (BLM). BLM-Schriftenreihe Band 85. München: Reinhard Fischer 